\title{
Are Cover Stories Effective Contrarian Indicators?
}

\author{
Tom Arnold, CFA, John H. Earl, Jr., CFA, and David S. North
}

\begin{abstract}
Headlines from featured stories in Business Week, Fortune, and Forbes were collected for a 20-year period to determine whether positive stories are associated with superior future performance and negative stories are associated with inferior future performance for the featured company. "Superior" and "inferior" were determined in comparison with an index or another company in the same industry and of the same size. Statistical testing implied that positive stories generally indicate the end of superior performance and negative news generally indicates the end of poor performance.
\end{abstract}

$\mathbf{T}$ he covers of business magazines have been considered informative as a potential contrarian signal (e.g., Stalter 2005; Forsyth 1996, 1997; Queenan 1991). Aside from anecdotal evidence and a few factual examples, however, such a view has never been validated statistically. Others have studied specific business analysts or television programs (e.g., Desai and Jain 2004; Ferreira and Smith 2003), tested the effect of company fortunes statistically, and demonstrated a limited effect on future short-term stock prices (many times only on the first day after the information was reported). We statistically tested the effect of business magazine cover stories (as identified by the cover headlines) on stock prices/returns for more than a 1,000-day horizon (500 days prior to and 500 days after publication; we excluded the publication date from the analysis). We investigated effects of cover stories from Business Week, Fortune, and Forbes for a 20-year period (1983-2002).

To formalize how a magazine cover article might affect future returns, one can assume that the given story reports new pertinent information or simply reports past information. If the information is genuinely new, the market can exhibit the following reactions:

- an instantaneous and correct reaction-that is, a very short term effect occurs but no lingering future effects;

- an underreaction-a potentially longer-term effect occurs that makes the story a momentum indicator;

- an overreaction-a potentially longer-term effect occurs that makes the story a contrarian indicator.

Tom Arnold, CFA, is assistant professor of finance at the University of Richmond, Virginia. John H. Earl, Jr., CFA, and David S. North are associate professors of finance at the University of Richmond, Virginia.
If the information contained in the article is not new, the market can have the following reactions:

- no reaction-that is, all information incorporated in prices;

- a reaction that coincides with the popularity of the stock-that is, a possible momentum indicator;

- a reaction that coincides with the stock being mispriced - that is, a possible contrarian indicator.

Most of the anecdotal evidence supports the idea that cover stories are not informational because of the time needed to gather information for the article and to print it. The availability of instantaneous business news and, to a lesser extent, daily business news outlets put weekly and biweekly (every two weeks) news magazines at a great disadvantage in providing new information about a company. Furthermore, the anecdotal evidence tends to view the scenario in which the article coincides with a stock being mispriced as giving credence to the idea that the magazine cover story is a contrarian indicator (again, assuming no new information is revealed in the article).

We carried out tests to determine whether cover stories are indicators of future performance (momentum or contrarian). We did not consider whether or not the given article revealed new information about the company. Our bias, based on the disadvantages of weekly and biweekly business news magazines in reporting news in a timely manner, was toward the hypothesis that cover stories do not reveal new information about a company.

\section{Cover Story Data and Analysis}

We analyzed companies that were the subject of feature (cover) stories in Business Week (weekly), Fortune (biweekly), and Forbes (biweekly) magazines between 1983 and 2002 for stock price performance 24 months prior to and 24 months after (i.e., 
500 business days on either side of) the date the feature story was published. For purposes of the analysis, the "publication date" was the date on the cover minus 7 calendar days for Business Week and minus 14 calendar days for Fortune and Forbes. In other words, the publication date was considered to be equivalent to the first day the magazine was available to readers.

We categorized the cover headline of the feature story according to a five-point scale $(1=$ very positive, 2 = positive/optimistic, $3=$ neutral, $4=$ negative, and $5=$ very negative). Although the determination of whether a story was positive or negative appears to be quite subjective, the cover headlines of the stories clearly followed particular patterns:

- Category 1: Company A "is" or "has done" something innovative or profitable (very positive cover).

- Category 2: Company A "plans to do" or "is in the process of doing" something innovative for the future, but will it work? (optimistic cover).

- Category 3: The cover gives no particular opinion as to whether Company $\mathrm{A}$ is good or bad (companies are identified on the cover, but the cover gives no indication of a positive or negative slant to the feature).

- Category 4: Company A has experienced "poor performance," but the end of the poor performance may be near (pessimistic past but a turnaround is predicted).
- Category 5: Company A is doing very poorly, or a scandal has occurred (pessimistic cover, sometimes implying a future management change and/or litigation).

In addition to the clear tone of the cover headlines, the large sample should smooth individual misinterpretations that may have occurred in categorizing the feature stories.

There were 593 feature stories during the 20year time period, for which 4 years of stock returns for 549 subject companies were available for testing. ${ }^{1}$ Table 1 displays the frequency of positive (Categories 1 or 2), neutral (Category 3 ), and negative (Categories 4 or 5) feature stories in the period, in total and by periodical. Note that, in general, magazine feature stories do not focus on specific corporations. This aspect is demonstrated by the fact that out of a potential of 2,080 cover stories, only 593 focused on a particular corporation. Also, feature stories tend to be positive; 350 of the 549 sample feature headlines (63.7 percent) were definitely positive, and only 100 of the 549 sample feature stories (18.2 percent) were definitely negative.

Table 2 provides characteristics of the companies featured in the cover stories. The companies tended to be large, without much variability in size between the three periodicals. This characteristic is not surprising because the magazines tend to have similar readerships.

Table 1. Feature Story Frequency, 1983-2002

\begin{tabular}{|c|c|c|c|c|c|c|c|}
\hline \multirow[b]{2}{*}{ Periodical } & \multicolumn{3}{|c|}{ Positive Categories } & \multirow{2}{*}{$\begin{array}{c}\begin{array}{c}\text { Neutral } \\
\text { Category }\end{array} \\
3\end{array}$} & \multicolumn{3}{|c|}{ Negative Categories } \\
\hline & 1 & 2 & Total & & 4 & 5 & Total \\
\hline $\begin{array}{l}\text { Business Week } \\
\text { (273 features) }\end{array}$ & $\begin{array}{c}62 \\
(21 \%)\end{array}$ & $\begin{array}{l}97 \\
(33 \%)\end{array}$ & $\begin{array}{l}159 \\
(54 \%)\end{array}$ & $\begin{array}{l}57 \\
(20 \%)\end{array}$ & $\begin{array}{c}38 \\
(13 \%)\end{array}$ & $\begin{array}{l}36 \\
(12 \%)\end{array}$ & $\begin{array}{l}74 \\
(26 \%)\end{array}$ \\
\hline $\begin{array}{l}\text { Fortune } \\
\qquad(146 \text { features) }\end{array}$ & $\begin{array}{c}76 \\
(49 \%)\end{array}$ & $\begin{array}{l}44 \\
(28 \%)\end{array}$ & $\begin{array}{l}120 \\
(77 \%)\end{array}$ & $\begin{array}{l}24 \\
(15 \%)\end{array}$ & $\begin{array}{l}3 \\
(2 \%)\end{array}$ & $\begin{array}{l}9 \\
(6 \%)\end{array}$ & $\begin{array}{l}12 \\
(8 \%)\end{array}$ \\
\hline $\begin{array}{l}\text { Forbes } \\
\qquad \text { (90 features) }\end{array}$ & $\begin{array}{c}47 \\
(46 \%)\end{array}$ & $\begin{array}{l}24 \\
(23 \%)\end{array}$ & $\begin{array}{l}71 \\
(69 \%)\end{array}$ & $\begin{array}{l}18 \\
(17 \%)\end{array}$ & $\begin{array}{l}7 \\
(7 \%)\end{array}$ & $\begin{array}{l}7 \\
(7 \%)\end{array}$ & $\begin{array}{l}14 \\
(14 \%)\end{array}$ \\
\hline $\begin{array}{l}\text { Total } \\
\quad \text { (549 features) }\end{array}$ & $\begin{array}{l}185 \\
(34 \%)\end{array}$ & $\begin{array}{l}165 \\
(30 \%)\end{array}$ & $\begin{array}{l}350 \\
(64 \%)\end{array}$ & $\begin{array}{l}99 \\
(18 \%)\end{array}$ & $\begin{array}{l}48 \\
(9 \%)\end{array}$ & $\begin{array}{l}52 \\
(9 \%)\end{array}$ & $\begin{array}{l}100 \\
(18 \%)\end{array}$ \\
\hline
\end{tabular}

Table 2. Size of Companies Featured on Covers, 1983-2002 (market capitalization in \$ millions)

\begin{tabular}{lcccc}
\hline Company Characteristic & Business Week & Fortune & Forbes & Total \\
\hline Market-cap mean & $43,653.6$ & $52,371.4$ & $38,112.6$ & $45,091.1$ \\
Market-cap median $^{\text {Adjusted market-cap mean }}{ }^{\mathrm{a}}$ & $14,365.2$ & $19,781.2$ & $16,771.3$ & $15,112.3$ \\
Adjusted market-cap median $^{\mathrm{a}}$ & $49,532.3$ & $61,312.5$ & $41,651.5$ & $51,401.5$ \\
\hline
\end{tabular}

${ }^{a}$ Adjusted to 2002 U.S. dollars using the U.S. Consumer Price Index. 
To analyze the effect of a given feature story on a company, we calculated prior-period holdingperiod returns for 1 month ( -21 to -1 trading days), 6 months ( -125 to -1 trading days), 12 months ( -250 to -1 trading days), and 24 months ( -500 to -1 trading days) prior to the publication of the story. We calculated similar postpublication holding periods, with an additional holding period of 1 day to 5 days (to examine short-term effects). We excluded the day on which the feature story was published from the holding-period returns to allow for testing of cover stories as contrarian or momentum indicators. Specifically, our goal was to measure something more "predictive" of the future, in the sense of allowing a specific trading strategy to succeed, than a "quick" adjustment by the market.

Table 3 displays the average holding-period return (HPR) for all companies within a category for various time horizons before and after publication dates. The "adjusted return" (AR) is the average of the holding-period return minus the equivalent holding-period return for the value-weighted CRSP

Table 3. Holding-Period Returns for Three Groups, Data for 1983-2002 (measured in percentages)

\begin{tabular}{|c|c|c|c|c|c|c|c|c|c|}
\hline \multirow[b]{2}{*}{ Category/Measure } & \multicolumn{9}{|c|}{ Period from Publication (in trading days) } \\
\hline & -500 to -1 & -250 to -1 & -125 to -1 & -21 to -1 & 1 to 5 & 1 to 21 & 1 to 125 & 1 to 250 & 1 to 500 \\
\hline \multicolumn{10}{|c|}{ Positive categories-1 or $2(n=338)^{\mathrm{a}}$} \\
\hline HPR & 111.07 & 43.68 & 19.19 & 2.34 & 1.25 & 1.16 & 9.01 & 18.23 & 37.63 \\
\hline$t$-Statistic & $7.47^{* * *}$ & $9.97^{* * *}$ & $8.10^{* * *}$ & $2.97^{* * *}$ & $3.35^{* * *}$ & 1.63 & $4.70^{* * *}$ & $5.85^{* * *}$ & $5.90^{* * *}$ \\
\hline Signed rank-sum test & $13.26^{* * *}$ & $11.05^{* * *}$ & $8.24^{* * *}$ & $2.35^{* *}$ & $3.33^{* * *}$ & 1.60 & $4.66^{* * *}$ & $5.60^{* * *}$ & $6.79^{* * *}$ \\
\hline $\mathrm{AR}$ & 79.58 & 28.17 & 11.94 & 1.13 & 0.72 & -0.11 & 2.97 & 5.93 & 12.92 \\
\hline$t$-Statistic & $5.42^{* * *}$ & $6.75^{* * *}$ & $5.59^{* * *}$ & 1.59 & $2.27^{* *}$ & 0.18 & $1.69^{*}$ & $2.07^{* *}$ & $2.13^{* *}$ \\
\hline Signed rank-sum test & $8.66^{* * *}$ & $7.00^{* * *}$ & $4.88^{* * *}$ & 0.49 & $1.77^{*}$ & 0.47 & 0.85 & 0.47 & 0.24 \\
\hline AHPAR-ISM & 24.97 & 11.11 & 5.00 & 0.87 & 0.39 & -0.36 & 5.13 & 3.85 & 11.48 \\
\hline t-Statistic & 1.45 & $2.14^{* *}$ & $1.81^{*}$ & 0.97 & 0.82 & 0.42 & $2.51^{* *}$ & 1.18 & $1.65^{*}$ \\
\hline Signed rank-sum test & $2.75^{* * *}$ & $2.49^{* *}$ & $2.16^{* *}$ & 0.34 & 1.26 & 1.04 & $1.78^{*}$ & 1.02 & 1.05 \\
\hline \multicolumn{10}{|l|}{ Neutral Category $3(n=98)^{\mathrm{b}}$} \\
\hline HPR & 131.00 & 56.60 & 20.13 & 3.77 & 0.06 & 3.94 & 13.31 & 26.83 & 43.37 \\
\hline$t$-Statistic & $2.81^{* * *}$ & $3.40^{* * *}$ & $3.67^{* * *}$ & $2.38^{* *}$ & 0.10 & $1.69^{*}$ & $3.68^{* * *}$ & $3.58^{* * *}$ & $4.99^{* * *}$ \\
\hline Signed rank-sum test & $6.73^{* * *}$ & $5.43^{* * *}$ & $3.81^{* * *}$ & $2.05^{* *}$ & 0.36 & 1.42 & $3.87^{* * *}$ & $3.64^{* * *}$ & $4.98^{* * *}$ \\
\hline $\mathrm{AR}$ & 96.90 & 40.83 & 13.22 & 2.01 & -0.36 & 1.85 & 5.34 & 14.47 & 17.87 \\
\hline$t$-Statistic & $2.09^{* *}$ & $2.48^{* *}$ & $2.50^{* *}$ & 1.49 & 0.66 & 0.84 & 1.59 & $2.04^{* *}$ & $2.25^{* *}$ \\
\hline Signed rank-sum test & $2.06^{* *}$ & $2.29^{* *}$ & $1.66^{*}$ & 1.29 & 1.11 & 0.33 & 1.55 & 1.01 & 1.03 \\
\hline AHPAR-ISM & 2.11 & 14.11 & 9.52 & 2.23 & -0.33 & 1.24 & 4.66 & 8.88 & 12.61 \\
\hline$t$-Statistic & 0.03 & 0.83 & $1.87^{*}$ & 1.46 & 0.64 & 0.59 & 1.04 & 1.57 & 1.42 \\
\hline Signed rank-sum test & $2.30^{* *}$ & 1.40 & 1.53 & 1.49 & 1.04 & 0.85 & 1.02 & 1.52 & 1.59 \\
\hline \multicolumn{10}{|c|}{ Negative categories -4 or $5(n=96)^{\mathrm{C}}$} \\
\hline $\mathrm{HPR}$ & 6.11 & -2.12 & -0.72 & -0.31 & 1.53 & 0.87 & 2.98 & 13.18 & 31.75 \\
\hline$t$-Statistic & 1.08 & 0.55 & 0.23 & 0.21 & $1.98^{* *}$ & 0.69 & 1.23 & $3.18^{* * *}$ & $4.42^{* * *}$ \\
\hline Signed rank-sum test & 0.48 & 0.16 & 0.40 & 0.20 & $2.25^{* *}$ & 0.42 & 1.18 & $2.83^{* * *}$ & $4.27^{* * *}$ \\
\hline $\mathrm{AR}$ & -23.15 & -15.96 & -8.67 & -2.04 & 1.11 & 0.30 & -0.50 & 3.58 & 8.23 \\
\hline$t$-Statistic & $4.79^{* * *}$ & $4.70^{* * *}$ & $2.73^{* * *}$ & 1.15 & $1.73^{*}$ & 0.29 & 0.24 & 0.94 & 1.25 \\
\hline Signed rank-sum test & $4.80^{* * *}$ & $4.78^{* * *}$ & $2.86^{* * *}$ & 1.46 & $1.88^{*}$ & 0.08 & 0.53 & 0.04 & 0.24 \\
\hline AHPAR-ISM & -71.22 & -34.62 & -13.54 & -3.15 & 0.44 & -0.17 & 0.08 & 3.22 & 7.91 \\
\hline t-Statistic & $3.34^{* * *}$ & $4.36^{* * *}$ & $3.66^{* * *}$ & $1.68^{*}$ & 0.57 & -0.11 & 0.27 & 0.75 & 1.07 \\
\hline Signed rank-sum test & $4.85^{* * *}$ & $4.86^{* * *}$ & $3.41^{* * *}$ & 1.49 & 0.17 & 0.17 & 0.64 & 0.20 & 0.37 \\
\hline
\end{tabular}

Notes: $\mathrm{HPR}=$ holding-period return, AR = adjusted return, and AHPAR-ISM = average holding-period abnormal return. The $t$-statistics are for differences from zero. Signed rank-sum statistics are for Wilcoxon signed rank-sum tests for differences from zero.

${ }^{a}$ Twelve cover headlines were redundant because the companies were in Category 1 or 2 within the prior three months.

${ }^{b}$ One cover headline was redundant because the company was in Category 3 within the prior three months.

${ }^{c}$ Four cover headlines were redundant because the companies were in Category 1 or 2 within the prior three months.

*Significant at the 10 percent level.

**Significant at the 5 percent level.

***Significant at the 1 percent level. 
stock index. The "average holding-period abnormal return-industry and size matched" (AHPAR-ISM) is the average of the HPR of a given company minus the equivalent HPR of another company that was matched to it by size and industry (i.e., a non-coverstory equivalent company). ${ }^{2}$ These two measures provided adjustments to the initial HPR calculation to determine whether a positive or negative abnormal return was present.

For all return calculations, we attempted to eliminate duplicate observations, defined as a feature story happening fewer than three months after another feature for a given company and having the same categorization. We included the first instance and dropped the subsequent observation(s). ${ }^{3}$ Additionally, when a company was delisted after publication of the issue in which it was featured, we carried out the return calculation through the delisting date and included it in all calculations of holding-period returns.

Table 3 indicates that for companies with positive cover stories, positive holding-period returns existed before and after the publication date that are generally statistically significant (based on a $t$-test and a Wilcoxon signed rank-sum test). When the holding-period returns were adjusted for an index or for size/industry, however, most positive abnormal returns dissipated after the publication date. This result is not always the case; the AR measure displays some positive adjusted returns based on $t$-tests (a mean-based test) but not always based on the signed rank-sum test (a median-based test). The AHPAR-ISM measure displays a statistically significant positive adjusted return based on agreement by both statistical tests only for the six-month postpublication horizon.

In Table 4, where Category 1 and Category 2 companies are separately examined, much of the statistical significance vanishes except for the sixmonth horizon AHPAR-ISM measure for Category 2. Consequently, for companies that are the subject of optimistic cover stories, we found, at best, weak evidence of a momentum indicator over the sixmonth horizon.

For the companies with negative cover stories, Table 3 reports statistically negative adjusted holding-period returns for the two years (and periods of less than two years) prior to publication, except for one month prior to publication. After publication, the holding-period returns are no longer negative and, on an adjusted basis, tend to not be significantly different from zero. When Cat- egories 4 and 5 are presented separately in Table 4 , almost all statistical significance on an adjusted basis disappears. The holding-period return for the one-month period prior to publication for Category 5 companies, however, is significantly negative on an adjusted basis.

In summary, we found no signs that negative stories are a momentum or contrarian indicator. If a trader was shorting one of these stocks, however, the trader should have considered covering the short position after seeing a negative cover headline on the company because the stock hit its "bottom" level at that time.

To test the robustness of these results, we performed a calendar-time portfolio analysis. For each category and subperiod, we formed an equally weighted portfolio of companies; we rebalanced it every month for the entire sample period, January 1983 through December 2002. Over time, some companies dropped out of the portfolio as they were delisted. The results were consistent with Table $4 .{ }^{4}$

\section{Conclusion}

As one might expect, positive feature stories headlined on business magazine covers follow extremely positive company performance and negative headlines follow extremely negative performance. In both cases, however, the appearance on a cover of Business Week, Fortune, or Forbes tends to signal the end of the extreme performance. Going forward from publication dates, we found only weak evidence that optimistic cover stories (Category 2) are an indicator for momentum for a six-month horizon after publication. Negative cover headlines apparently do not provide a good signal for momentum or contrarian strategies when performance is measured against an index or measured on a size/ industry-adjusted basis-despite a popular belief that such stories are a contrarian signal. Indeed, companies in the study that were the subjects of negative feature stories tended to have positive holding-period returns after publication of the magazine, but the positive return was not abnormally positive when adjusted for an index or for size and industry. Consequently, we conclude that if an investor is short the stock of a company that is the subject of a negative cover story, the publication of the story indicates it is time to cover the short position because the stock has hit bottom.

This article qualifies for 1 PD credit. 
Table 4. Holding-Period Returns: Positive and Negative Categories, Data for 1983-2002 (measured in percentages)

\begin{tabular}{|c|c|c|c|c|c|c|c|c|c|}
\hline \multirow[b]{2}{*}{ Category/Measure } & \multicolumn{9}{|c|}{ Period from Publication (in trading days) } \\
\hline & -500 to -1 & -250 to -1 & -125 to -1 & -21 to -1 & 1 to 5 & 1 to 21 & 1 to 125 & 1 to 250 & 1 to 500 \\
\hline \multicolumn{10}{|c|}{ Positive Category $1(n=182)^{\mathrm{a}}$} \\
\hline HPR & 119.41 & 56.92 & 19.73 & 1.54 & 1.15 & 1.45 & 8.13 & 17.37 & 29.81 \\
\hline t-Statistic & $5.70^{* * *}$ & $7.41^{* * *}$ & $5.77^{* * *}$ & $1.78^{*}$ & $2.20^{* *}$ & $1.69^{*}$ & $3.66^{* *}$ & $3.86^{* * *}$ & $5.16^{* * *}$ \\
\hline Signed rank-sum test & $10.50^{* * *}$ & $9.00^{* * *}$ & $6.53^{* * *}$ & 1.30 & $2.24^{* *}$ & $1.70^{*}$ & $3.21^{* * *}$ & $3.58^{* * *}$ & $4.87^{* * *}$ \\
\hline $\mathrm{AR}$ & 88.82 & 32.01 & 13.02 & 0.64 & 0.79 & -0.03 & 1.82 & 4.63 & 5.07 \\
\hline$t$-Statistic & $4.29^{* * *}$ & $5.31^{* * *}$ & $4.19^{* * *}$ & 0.78 & 1.56 & 0.06 & 0.87 & 1.09 & 0.93 \\
\hline Signed rank-sum test & $8.00^{* * *}$ & $6.575^{* * *}$ & $4.62^{* * *}$ & 0.04 & 1.20 & 0.05 & 0.04 & 0.38 & 0.77 \\
\hline AHPAR-ISM & 42.71 & 17.63 & 8.25 & 1.03 & 0.37 & -0.43 & 2.87 & 2.75 & 4.18 \\
\hline$t$-Statistic & $1.87^{*}$ & $2.40^{* *}$ & $2.05^{* *}$ & 0.93 & 0.50 & 0.51 & 1.26 & 0.62 & 0.59 \\
\hline Signed rank-sum test & $3.91^{* * *}$ & $3.36^{* * *}$ & $2.92^{* * *}$ & 0.51 & 0.38 & 0.91 & 0.19 & 0.06 & 0.34 \\
\hline \multicolumn{10}{|c|}{ Positive Category $2(n=162)^{b}$} \\
\hline HPR & 105.61 & 39.92 & 18.65 & 3.23 & 1.22 & 0.51 & 9.57 & 19.59 & 45.76 \\
\hline$t$-Statistic & $5.02^{* * *}$ & $6.89^{* * *}$ & $5.84^{* * *}$ & $2.39 * *$ & $2.55^{* *}$ & 0.51 & $3.04^{* * *}$ & $4.59 * * *$ & $3.92^{* * *}$ \\
\hline Signed rank-sum test & $8.23^{* * *}$ & $6.71^{* * *}$ & $5.27^{* * *}$ & $2.08^{* *}$ & $1.97^{* *}$ & 0.21 & $3.24^{* * *}$ & $4.32^{* * *}$ & $4.79^{* * *}$ \\
\hline $\mathrm{AR}$ & 73.37 & 23.78 & 10.93 & 1.68 & 0.51 & -0.21 & 4.11 & 7.92 & 21.43 \\
\hline$t$-Statistic & $3.54^{* * *}$ & $4.32^{* * *}$ & $3.81^{* * *}$ & 1.35 & 1.48 & 0.27 & 1.44 & $2.11^{* *}$ & $1.93^{*}$ \\
\hline Signed rank-sum test & $4.28^{* * *}$ & $3.42^{* * *}$ & $2.45^{* *}$ & 0.69 & 0.94 & 0.73 & 1.07 & 1.08 & 0.38 \\
\hline AHPAR-ISM & 4.12 & 1.72 & 0.03 & 0.22 & 0.37 & -0.16 & 7.46 & 5.15 & 18.54 \\
\hline$t$-Statistic & 0.16 & 0.25 & 0.01 & 0.23 & 0.75 & 0.10 & $2.16^{* *}$ & 1.11 & 1.53 \\
\hline Signed rank-sum test & 0.05 & 0.10 & 0.16 & 0.17 & 1.45 & 0.51 & $2.30^{* *}$ & 1.39 & 0.99 \\
\hline \multicolumn{10}{|c|}{ Negative Category $4(n=47)^{\mathrm{c}}$} \\
\hline HPR & 7.11 & 1.61 & 4.44 & 4.27 & 0.78 & 0.285 & 0.12 & 6.89 & 23.66 \\
\hline$t$-Statistic & 0.88 & 0.36 & 1.06 & $1.75^{*}$ & 1.01 & 0.19 & 0.02 & 1.50 & $3.29^{* * *}$ \\
\hline Signed rank-sum test & 0.11 & 0.27 & 0.23 & 1.37 & 0.92 & 0.27 & 0.11 & 1.39 & $2.76^{* * *}$ \\
\hline AR & -21.13 & -11.40 & -3.17 & 2.14 & 0.81 & -0.20 & -2.58 & 0.20 & 4.01 \\
\hline$t$-Statistic & $2.90^{* * *}$ & $2.78^{* * *}$ & 0.78 & 0.92 & 1.23 & 0.15 & 0.39 & 0.05 & 0.60 \\
\hline Signed rank-sum test & $3.20^{* * *}$ & $2.83^{* * *}$ & 1.11 & 0.26 & 1.06 & 0.25 & 0.83 & 0.50 & 0.21 \\
\hline AHPAR-ISM & -111.03 & -46.10 & -12.67 & 0.645 & -0.58 & -2.88 & -2.18 & 0.72 & 5.91 \\
\hline$t$-Statistic & $2.65^{* * *}$ & $3.14^{* * *}$ & $2.22^{* *}$ & 0.25 & 0.70 & $1.89^{*}$ & 0.48 & 0.14 & 0.63 \\
\hline Signed rank-sum test & $3.54^{* * *}$ & $3.23^{* * *}$ & $1.84^{*}$ & 0.20 & 1.01 & 1.40 & 0.15 & 0.02 & 0.50 \\
\hline \multicolumn{10}{|l|}{ Negative Category $5(n=52)$} \\
\hline $\mathrm{HPR}$ & 4.62 & -6.33 & -6.21 & -4.73 & 1.81 & 1.14 & 5.27 & 18.78 & 39.63 \\
\hline$t$-Statistic & 0.60 & 1.10 & 1.21 & $1.89^{*}$ & 1.56 & 0.65 & 1.57 & $2.92^{* * *}$ & $3.39^{* * *}$ \\
\hline Signed rank-sum test & 0.41 & 0.72 & 1.05 & 1.09 & $1.93^{*}$ & 0.12 & 1.51 & $2.65^{* * *}$ & $3.34^{* * *}$ \\
\hline $\mathrm{AR}$ & -25.22 & -20.44 & -14.57 & -5.85 & 1.38 & 0.79 & 0.79 & 5.98 & 12.03 \\
\hline$t$-Statistic & $4.09^{* * *}$ & $4.03^{* * *}$ & $3.17^{* * *}$ & $2.44^{* *}$ & 1.17 & 0.44 & 0.22 & 1.00 & 1.12 \\
\hline Signed rank-sum test & $3.63^{* * *}$ & $4.01^{* * *}$ & $2.93^{* * *}$ & $2.53^{* *}$ & 1.37 & 0.13 & 0.32 & 0.24 & 0.24 \\
\hline AHPAR-ISM & -34.63 & -23.72 & -15.41 & -6.78 & 1.25 & 2.22 & 2.98 & 5.37 & 12.42 \\
\hline$t$-Statistic & $3.77^{* * *}$ & $3.76^{* * *}$ & $3.31^{* * *}$ & $2.76^{* * *}$ & 1.12 & 1.25 & 0.79 & 0.81 & 1.11 \\
\hline Signed rank-sum test & $3.50^{* * *}$ & $3.71^{* * *}$ & $3.17^{* * *}$ & $2.53^{* *}$ & 0.95 & 1.51 & 0.99 & 0.17 & 0.40 \\
\hline
\end{tabular}

Notes: See notes to Table 3.

a Three cover headlines were redundant because the companies were in Category 1 within the prior three months.

${ }^{b}$ Three cover headlines were redundant because the companies were in Category 2 within the prior three months.

${ }^{\mathrm{c}}$ One cover headline was redundant because the company was in Category 1 within the prior three months.

* Significant at the 10 percent level.

**Significant at the 5 percent level.

***Significant at the 1 percent level. 


\section{Notes}

1. For hypothesis testing, we used the 24 months prior to the feature story.

2. Size and industry match was based on market value of equity and two-digit SIC classification and was set as of the day of publication.

3. The results remained qualitatively similar whether these observations were deleted or not.

4. These tabulations are available through a link from this issue's contents page at www.cfapubs.org.

\section{References}

Desai, H., and P. Jain. 2004. "Long-Run Stock Returns Following Briloff's Analyses." Financial Analysts Journal, vol. 60, no. 2 (March/April):47-56.

Ferreira, E., and S. Smith. 2003. “’Wall \$treet Week': Information or Entertainment?" Financial Analysts Journal, vol. 59, no. 1 (January/February):45-53.

Forsyth, R. 1996. "On Borrowed Time: Why Investors Should Worry about Magazine's Cover on Fidelity." Barron's National Business and Financial Weekly, vol. 76, no. 40 (30 September):18.
1997. "Beware: Magazine Cover Stories about Fed Chairman Tend to Be Contrarian Indicators for Bonds." Barron's National Business and Financial Weekly, vol. 77, no. 28 (14 July):MW10.

Queenan, J. 1991. “Exotic Indicators-Give Paul Macrae Montgomery a Forecasting Edge." Barron's National Business and Financial Weekly, vol. 71, no. 22 (3 June).

Stalter, K. 2005. "Magazine Covers Often Signal the Top of a Great Stock's Rally." Investor's Business Daily (22 June):B07.

\section{[ADVERTISEMENT]}

